\title{
Application of real-time shear wave elastography in the assessment of male infertility
}

\author{
Jun $\mathrm{Cui}^{1 \wedge}$, Qiang $\mathrm{Du}^{2} \wedge$, Wei Fu ${ }^{3 \wedge}$ \\ ${ }^{1}$ Second Department of Urology, Department of Urology, Shengjing Hospital of China Medical University, Shenyang, China; ${ }^{2}$ Andrology Clinic of \\ Reproductive Medical Center, Shengjing Hospital of China Medical University, Shenyang, China; ${ }^{3}$ Department of Ultrasound, Shengiing Hospital \\ of China Medical University, Shenyang, China
}

Contributions: (I) Conception and design: W Fu; (II) Administrative support: J Cui; (III) Provision of study materials or patients: Q Du; (IV) Collection and assembly of data: J Cui; (V) Data analysis and interpretation: W Fu; (VI) Manuscript writing: All authors; (VII) Final approval of manuscript: All authors.

Correspondence to: Wei Fu. Department of Ultrasound, Shengjing Hospital of China Medical University, 36 Sanhao Street, Heping District, Shenyang 110004, China. Email: 18940258130@163.com.

Background: Shear wave elastography (SWE) is recognized as a suitable imaging modality for identifying
and characterizing testicular diseases. Recent exploration of SWE has focused on its feasibility in evaluating
histopathological changes in the testicular parenchyma, with researchers increasingly focusing on the
relationship between testicular stiffness and male fertility. In this study, we aimed to investigate the diagnostic
value of SWE for distinguishing the relationship between spermatogenic defects and testicular stiffness in
males of reproductive age.

Methods: This was a single center, cross-sectional study conducted from July 2017 to December 2019. A total of 1,116 consecutive patients who were voluntarily participating in in-vitro fertilization (IVF)-assisted conception at our hospital were recruited to the study. The cohort included 497 normozoospermia patients (Group I), 335 with normozoospermia and decreased motility and agglutination (Group II), 138 with oligozoospermia (Group III), 105 with non-obstructive azoospermia (Group-NOA), and 41 with obstructive azoospermia (Group-OA). We conducted SWE of each participant's testes and the testicular elastic modulus was calculated. The differences of testicular elastic modulus were compared among groups. Linear regression analysis was conducted to determine the correlation between sperm concentration and either testicular volume or testicular elastic modulus. Receiver operating characteristic (ROC) curves were drawn to evaluate the diagnostic efficiency of the maximum elastic modulus (Emax), mean elastic modulus (Emean), and maximum minus the minimum elastic modulus $\{\mathrm{E}[\max -\mathrm{min}]\}$.

Results: The Emax, Emean, and E[max-min] increased gradually in groups I, II, III, and Group-NOA, with statistical differences between groups $(\mathrm{P}<0.01)$. Testicular volume was shown to be positively correlated with sperm concentration $(\mathrm{r}=0.476 ; \mathrm{P}<0.01)$, while the Emax, Emean, and $\mathrm{E}[\mathrm{max}-\mathrm{min}]$ were negatively correlated with sperm concentration $(\mathrm{r}=-0.511,-0.357$, and -0.524 , respectively; $\mathrm{P}<0.01)$. The ROC curves were established based on the Emax, Emean, and E[max-min] and were used to distinguish Group-OA from Group-NOA. The areas under the ROC curve (AUCs) were 0.910, 0.863, and 0.900, respectively. We also used ROC curves to distinguish the severe oligozoospermia subgroup and Group-NOA from other groups, for which the AUCs were $0.877,0.791$, and 0.878 , respectively.

Conclusions: The SWE is an effective supplement to routine ultrasound examination and can be used to diagnose and differentiate spermatogenetic dysfunction.

Keywords: Infertility; male; shear wave elastography (SWE); testis; ultrasonography

\footnotetext{
^ ORCID: Jun Cui, 0000-0001-7060-8263; Qiang Du, 0000-0002-7551-1994; Wei Fu, 0000-0002-2443-6760.
} 
Submitted Jun 18, 2021. Accepted for publication Oct 20, 2021.

doi: 10.21037/qims-21-648

View this article at: https://dx.doi.org/10.21037/qims-21-648

\section{Introduction}

An estimated 48.5 million couples worldwide are currently classified as infertile (1). Analysis of data from the Third National Survey of Sexual Attitudes and Lifestyles in Britain found that $10.1 \%$ of male participants aged $16-74$ reported failure to impregnate their partner after having attempted to do so for a year or longer (2). In recent years, the issue of male infertility has attracted widespread attention.

Shear wave elastography (SWE) is a medical imaging modality that can noninvasively measure tissue stiffness and improve diagnostic performance. It uses ultra-fast ultrasound tracking technology and Young's modulus formula to display elastic images in real-time, allowing the stiffness of tissue to be shown through different colors. As a useful adjunct to conventional ultrasound, SWE is widely used in the diagnosis of breast tumors, thyroid tumors, lymph node diseases, and other superficial organ diseases (3-7).

The SWE is an acceptable imaging modality for identifying and characterizing testicular diseases. To our knowledge, there have been many studies on the application of SWE in normal testis (8-10), and these researches have provided a firm foundation for further systematic investigations. Currently, the feasibility of SWE for evaluating histopathological changes of testicular parenchyma is a hotspot in research focusing on varicocele (11-13), undescended testes (14), and testicular microlithiasis $(10,15,16)$. The testicular stiffness of men with the above scrotal diseases can be reflected by SWE with good reliability and repeatability. In recent years, more researchers have paid attention to the relationship between testicular stiffness and male fertility (17-19); however, their findings have been controversial. Such studies have also been limited by their relatively small sample sizes and statistically weak results. Therefore, further research in this area is still necessary.

For this reason, our present study enrolled a large sample size of reproductive-aged men to evaluate the reliability of using SWE to quantify testicular stiffness and predict male infertility. We present the following article in accordance with the STROBE reporting checklist (available at https:// dx.doi.org/10.21037/qims-21-648).

\section{Methods}

\section{Participant screening and enrollment}

This single center, cross-sectional study was conducted in accordance with the Declaration of Helsinki (as revised in 2013) and approved by the Ethics Committee of Shengjing Hospital, China Medical University (2018PS104J). Written informed consent was provided by all participants. Prior to commencing the study, we estimated that a sample size of 1,008 participants would allow for a power (1-abeta) of $90 \%$ at a significance level of 0.01 . Initially, 1,695 men were recruited to the study. Each of these participants were engaged in their own respective in-vitro fertilization (IVF)assisted conception at our hospital's Reproductive Medical Center from July 2017 to December 2019. The inclusion criteria were as follows: (I) scrotal ultrasound and testicular SWE examination had been performed, and (II) semen analysis was completed within 7 days following ultrasound. The exclusion criteria were as follows: (I) testicular biopsy had been performed within the past 3 months; (II) radiotherapy or chemotherapy had been carried out within the past 2 years; (III) history of testicular trauma; (IV) history of urethral reconstruction surgery; (V) abnormal ultrasound findings (testicular masses, cryptorchidism, varicocele, extensive microlithiasis, hydrocele, solitary testis, inguinal hernia); (VI) ejaculation disorder; (VII) obstructive azoospermia (OA) and non-obstructive azoospermia (NOA) could not be distinguished; and (VIII) satisfactory images were unobtainable (for various reasons). According to these criteria, a total of 1,116 participants were finally enrolled in the study.

\section{Participant grouping and subgrouping}

According to the criteria outlined in the World Health Organization (WHO) manual for the standardized investigation, diagnosis, and management of the infertile male (fifth edition), participants were allocated to the following groups:

Group I: normozoospermia group (semen volume $\geq 1.5 \mathrm{~mL}$, sperm concentration $\geq 15 \times 10^{6} / \mathrm{mL}$, progressive motility $\geq 32 \%$, and normal form sperm morphology $\geq 4 \%$ ).

Group II: normozoospermia with decreased motility 
and agglutination, participants with asthenozoospermia, teratozoospermia, and asthenoteratozoospermia (semen volume $\geq 1.5 \mathrm{~mL}$, sperm concentration $\geq 15 \times 10^{6} / \mathrm{mL}$; progressive motility $\leq 32 \%$, or progressive + non-progressive motility $<40 \%$, and/or normal form sperm morphology $\leq 4 \%$ ).

Group III: oligozoospermia group (sperm concentration $<15 \times 10^{6} / \mathrm{mL}$ ). Participants in this group were divided into two subgroups, either severe (sperm concentration $<5 \times 10^{6} / \mathrm{mL}$ ) or mild (sperm concentration $5 \times 10^{6} / \mathrm{mL}-15 \times 10^{6} / \mathrm{mL}$ ) (20).

Group IV: azoospermia group. Participants in this group were divided into two subgroups, an obstructive azoospermia group (Group-OA) and a non-obstructive azoospermia group (Group-NOA). We distinguished OA and NOA by considering the history, physical examination, endocrine analysis, genetic testing, and histological examination of each participant.

\section{Instruments and methods}

Testicular stiffness was evaluated using an ultrasound diagnostic imaging system, Aixplorer (SuperSonic Imagine, Aix en Provence, France), with a 4-15 $\mathrm{MHz}$ linear transducer. All ultrasound examinations and real-time SWE were conducted by an experienced sonographer (W Fu) who had 13 years of experience in andrology ultrasound.

Participants were examined in the supine position. Grayscale ultrasonography of the scrotum was performed first. Scrotal contents were examined, and testicular volume was calculated with the formula: testicular volume $(\mathrm{mL})=($ length $\times$ width $\times$ height $) \times 0.71(21)$. Testicular volume was defined as the average volume of both testes.

For SWE imaging, gray-scale images in the maximum longitudinal plane were obtained first, and thereafter, the imaging mode was changed to the elastography mode. This allowed real-time elastographic and gray-scale images to simultaneously appear up-and-down on the screen (Figure 1). A modulus of elasticity was displayed with an SWE map in $\mathrm{kPa}$ (range, 0 to $180 \mathrm{kPa}$ ). We obtained three consecutive measurements in the middle of the testis with a $10 \mathrm{~mm}$ region of interest (ROI). This included the maximum elastic modulus (Emax), minimum elastic modulus (Emin), and mean elastic modulus (Emean). If the size of the ROI was found to be small, it was adapted to the testicular volume. The Emax minus Emin was defined as the E[max-min]. We took the average of the three measurements as the unilateral testicular elastic modulus. The average values of Emax, Emean, Emin, and E[max-min] of both testes were recorded as the testicular elastic modulus values of participants.
Semen samples were collected by masturbatory ejaculation into a sterile container in a semen collection room after 3-7 days of abstinence. The samples were then assessed for sperm parameters and evaluated according to the values established by the WHO in 2010. In the case of an abnormal result, a repeat semen analysis was offered 7 days after the first sample, and the better result was used for further analysis.

\section{Statistical analysis}

Statistical analysis was performed using SPSS version 20.0 (SPSS Inc., Chicago, IL, USA). Data were presented as median and quartiles (Q1, Q3). Statistical differences were analyzed by the Mann-Whitney $U$ test for comparison between two groups, and the Kruskal Wallis test for comparison of multiple groups. A linear regression analysis was conducted, and Spearman's rank correlation coefficient was calculated to determine the correlation between sperm concentration and either testicular volume or testicular elastic modulus. Receiver operating characteristic (ROC) curves were constructed to evaluate the diagnostic performance of the testicular elastic modulus. The areas under the ROC curve (AUCs), sensitivities, and specificities were calculated, and the cutoff values were determined by Youden index. A P value $<0.05$ indicated a statistically significant difference.

\section{Results}

\section{Flow diagram of participants}

Flow diagram of participants were shown in Figure 2.

\section{The distribution of Y-chromosome microdeletions at the azoospermia factor (AZF) locus, polymorphisms, and autosomal abnormalities (Table 1)}

No classical Y-chromosome microdeletions at the AZF locus were found in Group I, Group II, the mild oligozoospermia subgroup, and Group-OA, while their probability in the severe oligozoospermia subgroup and Group-NOA was $5.88 \%$ and $9.52 \%$, respectively. The probability of polymorphisms in Group I, Group II, the mild oligozoospermia subgroup, severe oligozoospermia subgroup, and Group-NOA was 2.62\%, 4.48\%, 2.86\%, $4.41 \%$, and $1.90 \%$, respectively (with no obvious trend). However, the probability of autosomal abnormalities in the above groups was $1.21 \%, 2.39 \%, 2.86 \%, 4.41 \%$, and 

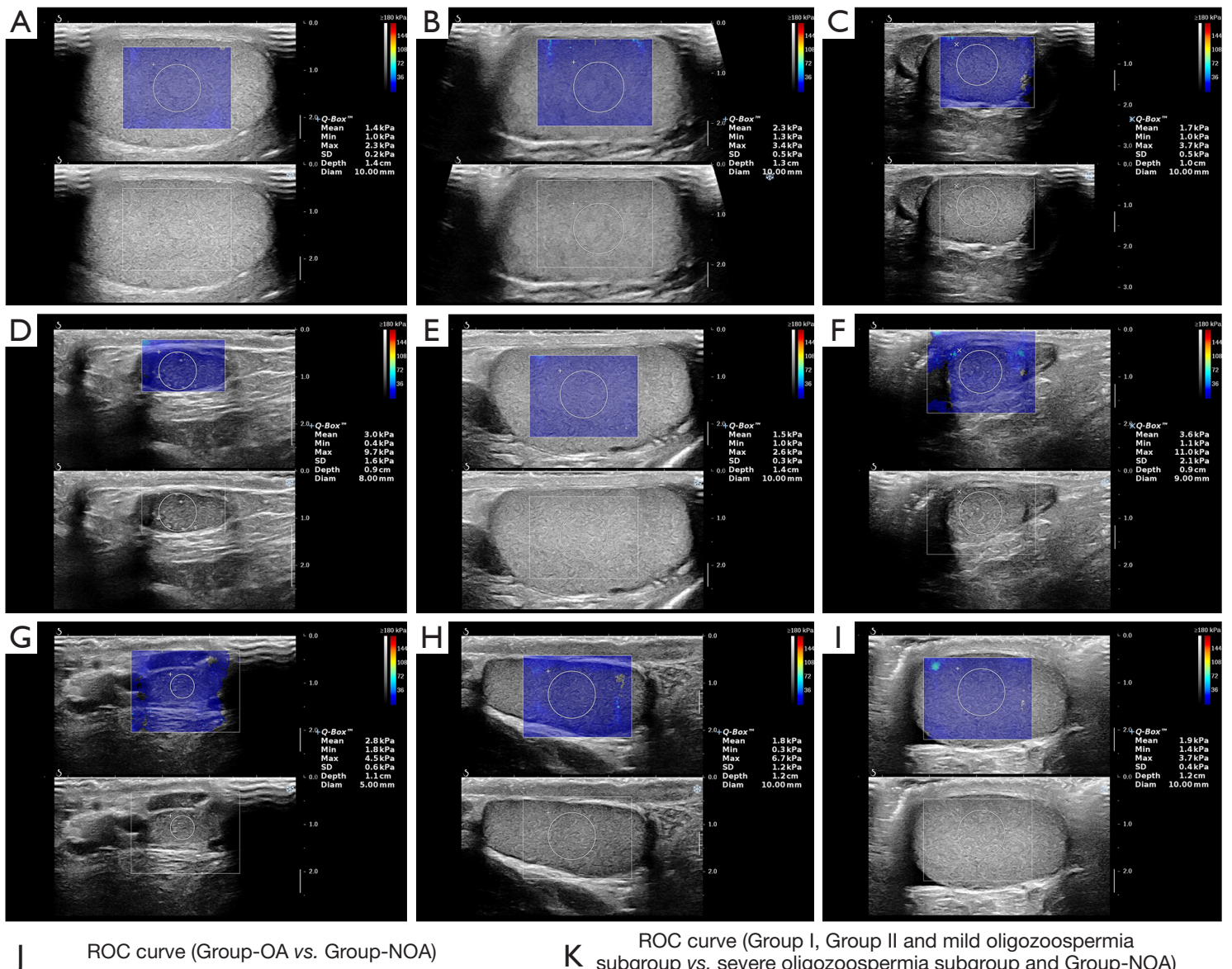

J

ROC curve (Group-OA vs. Group-NOA)

ROC curve (Group I, Group II and mild oligozoospermia

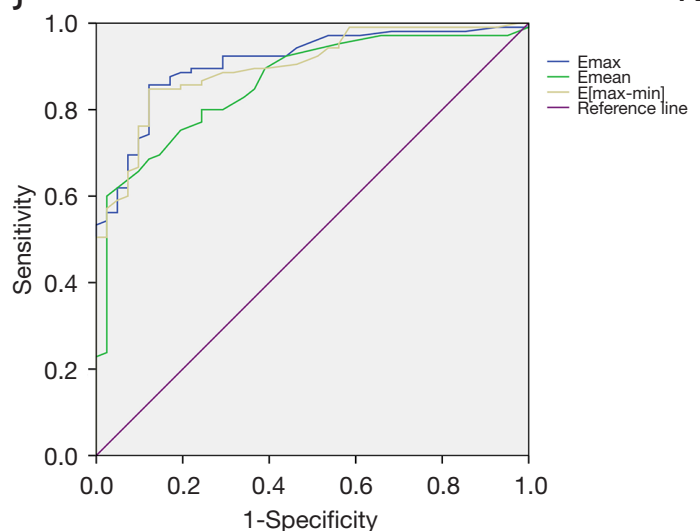

K subgroup vs. severe oligozoospermia subgroup and Group-NOA)

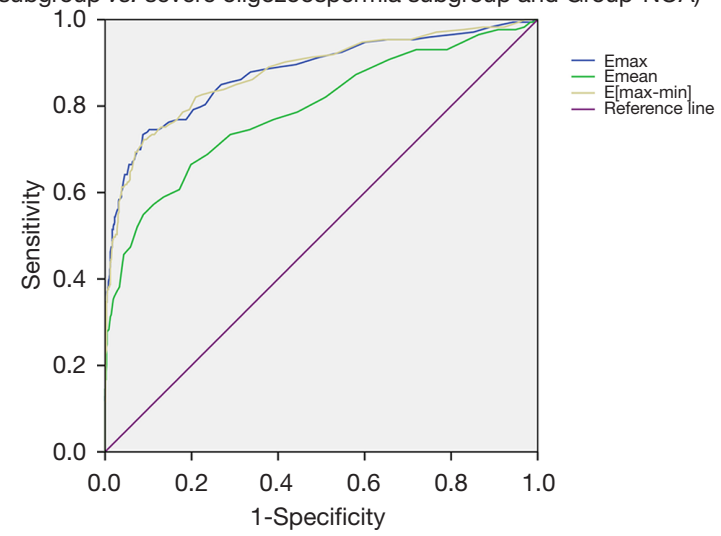

Figure 1 SWE maps and ROC curves. (A) A 35-year-old male with normozoospermia. (B) A 26-year-old male with mild oligozoospermia. (C) A 26-year-old male with severe oligozoospermia. Locus deletions at sY152, sY157, sY239, sY242, sY254, and sY255 of Y-chromosome. Average testicular volume was $8.00 \mathrm{~mL}$. Emax $=4.7 \mathrm{kPa}$, Emean $=1.85 \mathrm{kPa}$, Emin $=1.05 \mathrm{kPa}$. (D) A 34-year-old male with NOA. Pituitary microadenoma (diameter $=5 \mathrm{~mm}$ ) was found with MRI. Average testicular volume was $1.13 \mathrm{~mL}$. Testicular parenchyma was rough. Microlithiasis was found in both testes. Emax $=8.15 \mathrm{kPa}$, Emean $=3 \mathrm{kPa}$, Emin $=1.1 \mathrm{kPa}$. (E) A 39-year-old male with OA. Average testicular volume was $17.48 \mathrm{~mL}$. Testicular parenchyma was uniform. Bilateral epididymis enlargement, rough echo. Emax =2.3 kPa, Emean $=1.55 \mathrm{kPa}, \mathrm{Emin}=1.0 \mathrm{kPa}$. (F) A 35 -year-old male with KS, azoospermia. Chromosome karyotype was 47, XXY. Average testicular volume was $1.31 \mathrm{~mL}$. Testicular parenchyma was rough. Microlithiasis was found in the right testis. Emax $=9.75 \mathrm{kPa}$, Emean $=2.85 \mathrm{kPa}$, Emin $=0.5 \mathrm{kPa}$. (G) A 45 -year-old male with sexual inversion, azoospermia. Chromosome karyotype was 46,XX. Average testicular volume was $0.82 \mathrm{~mL}$. Testicular parenchyma was rough. Emax $=4.35 \mathrm{kPa}$, Emean $=2.4 \mathrm{kPa}$, Emin $=1.3 \mathrm{kPa}$. $(\mathrm{H})$ A 30 -year-old male with idiopathic azoospermia. Average testicular volume was $8.64 \mathrm{~mL}$. Testicular parenchyma was uniform. Emax $=16.2 \mathrm{kPa}$, Emean $=2.35 \mathrm{kPa}$, Emin $=0.3 \mathrm{kPa}$. (I) A 27-year-old male with SCOS. Average testicular volume was $7.43 \mathrm{~mL}$. Testicular parenchyma was uniform. Emax $=3.3 \mathrm{kPa}$, Emean $=1.85 \mathrm{kPa}$, Emin $=1.2 \mathrm{kPa}$. (J,K) ROC curve of Emax, Emean, and E[max-min]. SWE, shear wave elastography; ROC, receiver operating characteristic; Emean, mean elastic modulus; Emin, minimum elastic modulus; Emax, maximum elastic modulus; E[max-min], maximum minus the minimum elastic modulus; NOA, non-obstructive azoospermia; OA, obstructive azoospermia; SWE, shear wave elastography; MRI, magnetic resonance imaging; KS, Klinefelter syndrome; SCOS, Sertoli cell-only syndrome. 


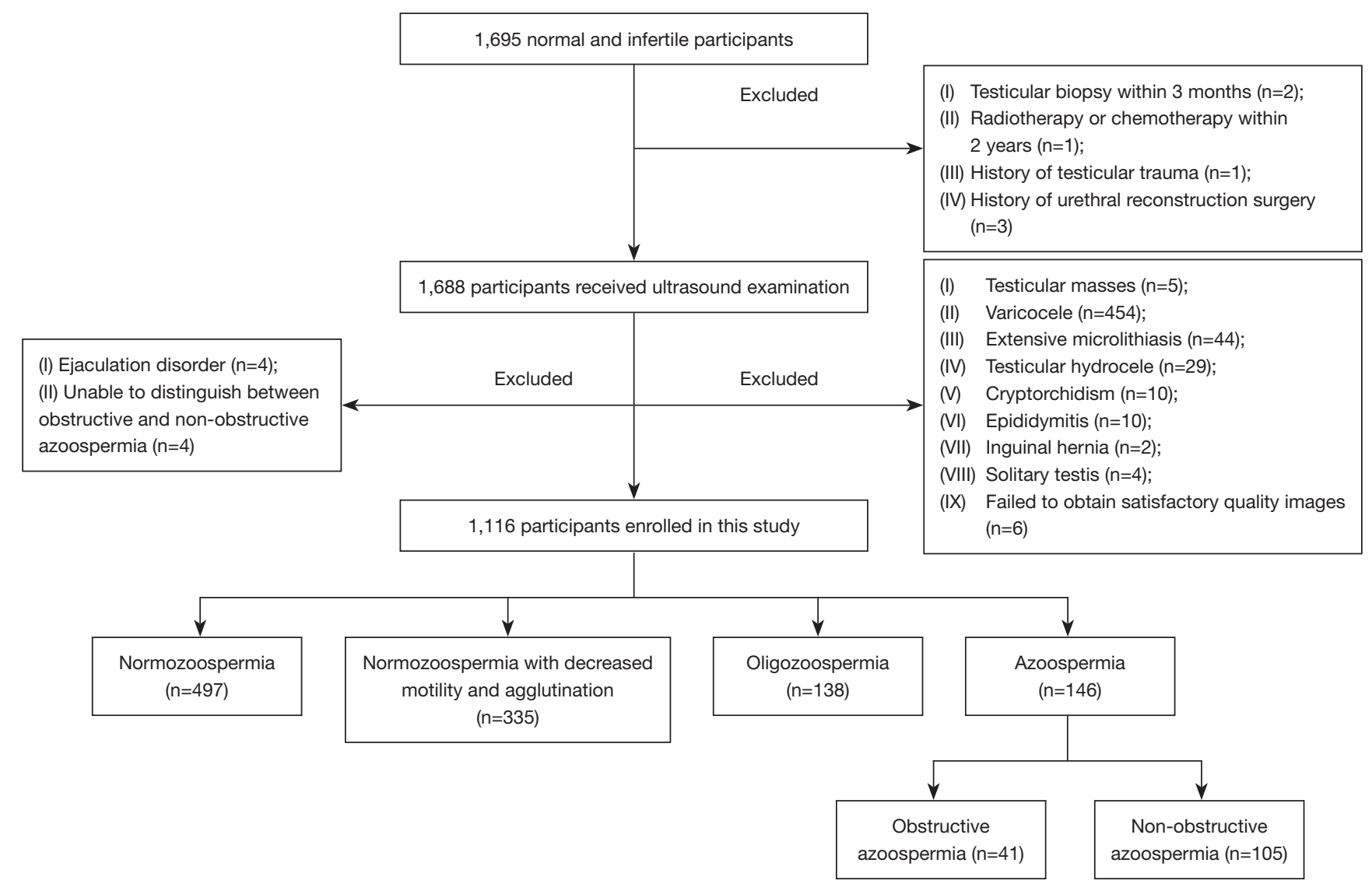

Figure 2 Participant enrollment and distribution.

$22.86 \%$, respectively, showing a significantly increasing trend. No polymorphisms and autosomal abnormalities were found in Group-OA.

\section{Comparison of age, testicular volume, and testicular elastic modulus among different groups (Table 2)}

\section{Age}

In terms of age, there were no significant differences among groups.

\section{Testicular volume}

Testicular volume decreased gradually in Group I, Group II, Group III, and Group-NOA participants, with statistical differences $(\mathrm{P}<0.01)$. Testicular volume in Group-OA participants were significantly greater than those in both Group III and Group-NOA $(\mathrm{P}<0.01)$, but there were no differences among Group-OA, Group I, and Group II ( $\mathrm{P}>0.05)$.

\section{Testicular elastic modulus \\ Emax}

The Emax increased gradually in Group I, Group II, Group III, and Group-NOA, with statistical differences among these groups $(\mathrm{P}<0.01)$. The Emax in Group-OA participants was significantly smaller than those in both Group III and Group-NOA $(\mathrm{P}<0.01)$, but there were no significant differences between the Emax of Group-OA participants and those in Group I and Group II $(\mathrm{P}>0.05)$.

\section{Emean}

The Emean increased gradually in Group I, Group II, Group III, and Group-NOA participants, but there was no statistical difference between those in Group I and Group II $(\mathrm{P}>0.05)$. There were significant differences between participants in Group III and both Group I and Group II $(\mathrm{P}<0.01)$, and there were also significant differences between group-NOA participants and those in Group I, Group II, and Group III $(\mathrm{P}<0.01)$. 
Table 1 Microdeletions of Y-chromosome at the AZF locus, polymorphisms, and autosomal abnormalities

\begin{tabular}{|c|c|c|c|}
\hline Group & Y-chromosome microdeletions & Polymorphisms & Autosomal abnormalities \\
\hline Group I & Absence & $2.62 \%(13 / 497)$ & $1.21 \%(6 / 497)$ \\
\hline Group II & Absence & $\begin{array}{l}\text { Two 46,XY,14ps+; 46,XY (14pstk+); } \\
\text { 46,XY (big Y); two 46,XY (1qh+); } \\
\text { two 46,XY (22ps+); two 46,XY qh-; } \\
\text { two 46,XY (9qh+); 46,XYqh+; 46,XY } \\
\text { (16qh+); 46,XY (14ps+)(16qh+) }\end{array}$ & $\begin{array}{l}\text { Five 46,XY,inv(9)(p12q13); } \\
\text { 46,XY,t(1;3)(p21;p13); 46,XY,inv(17) } \\
\text { (p11.2p12); 46XY t(5;11)(q14;q21) }\end{array}$ \\
\hline \multirow[t]{2}{*}{$\begin{array}{l}\text { Mild } \\
\text { oligozoospermia }\end{array}$} & \multirow[t]{2}{*}{ Absence } & 46,XY (9qh+); 46XY (small Y) & $\begin{array}{l}\text { 46XY,t(1;21)(q41;q21); 46,XY,inv(9) } \\
(\mathrm{p} 12 \mathrm{q} 13)\end{array}$ \\
\hline & & $2.86 \%(2 / 70)$ & $2.86 \%(2 / 70)$ \\
\hline \multirow[t]{2}{*}{$\begin{array}{l}\text { Severe } \\
\text { oligozoospermia }\end{array}$} & $\begin{array}{l}3 \text { cases of locus deletions at } \\
\text { sY152, sY157, sY239, sY242, } \\
\text { sY254, sY255; locus deletions at } \\
\text { sY152, sY157, sY254, sY255 }\end{array}$ & $\begin{array}{l}46, X Y(1 q h+)(9 q h+) ; 46, X Y(15 p s+) \\
46, X Y(s m a l l ~ Y)\end{array}$ & $\begin{array}{l}\text { 46XY,inv(9)(p12q13); two 45XY, } \\
\operatorname{der}(13 ; 14)(q 10 ; q 10)\end{array}$ \\
\hline & $5.88 \%(4 / 68)$ & $4.41 \%(3 / 68)$ & $4.41 \%(3 / 68)$ \\
\hline \multirow[t]{2}{*}{ Group-NOA } & $\begin{array}{l}3 \text { locus deletions at sY152, sY157, } \\
\text { sY239, sY242, sY254, sY255; locus } \\
\text { deletions at sY152, sY157, sY254, } \\
\text { sY255; locus deletions at sY84, } \\
\text { sY86; } 3 \text { locus deletions at sY124, } \\
\text { sY127, sY134, sY143, sY145, } \\
\text { sY152, sY157, sY239, sY242, } \\
\text { sY254, sY255; } 2 \text { locus deletions at } \\
\text { sY84, sY86, sY124, sY127, sY134, } \\
\text { sY143, sY145, sY152, sY157, } \\
\text { sY239, sY242, sY254, sY255 }\end{array}$ & 46,XY (small Y?); 46,XY (15ps+) & $\begin{array}{l}\text { Seventeen 47XXY; two 46XX; } \\
\text { 46XY,t(13;14),(p12;q21); } \\
\text { 46XY,t(11;22)(q25;q13); 46XY,inv(9) } \\
\text { (p12q13); 46,XY,t(9;13)(p13;q14); } \\
\text { 45,X[6]/46,X,inv(Y)(q11q12)[14] }\end{array}$ \\
\hline & $9.52 \%(10 / 105)$ & $1.90 \%(2 / 105)$ & $22.86 \%(24 / 105)$ \\
\hline
\end{tabular}

Group I: normozoospermia; Group II: normozoospermia with decreased motility and agglutination. AZF, azoospermia factor; NOA, non-obstructive azoospermia.

The Emean in Group-OA participants was significantly smaller than that of those in Group III and Group-NOA $(\mathrm{P}<0.01)$, while the differences were not statistically significant compared with those in Group I and Group II $(\mathrm{P}>0.05)$.

\section{Emin}

There were no significant differences among groups for the Emin $(\mathrm{P}>0.05)$.

\section{E[max-min]}

The E[max-min] increased gradually in Group I, Group II, Group III, and Group-NOA participants, and there were statistical differences among the above groups $(\mathrm{P}<0.01)$. The $\mathrm{E}[\mathrm{max}-\mathrm{min}]$ in Group-OA participants was significantly smaller than those in Group III and Group-NOA $(\mathrm{P}<0.01)$, but there were no significant differences between the $\mathrm{E}$ [max-min] in Group-OA participants and those in Group 
Table 2 The median of age, testicular volume, Emean, Emin, Emax, E[max-min], total sperm count, and sperm concentration

\begin{tabular}{|c|c|c|c|c|c|c|}
\hline Items & Group I & Group II & Group III & Group-NOA & Group-OA & Total \\
\hline Age & $32[29,35]^{\dagger}$ & $33[30,37]$ & $31[28,34.25]$ & $30[28,33.5]$ & $31[28,34]$ & $32[29,35]$ \\
\hline $\begin{array}{l}\text { Testicular } \\
\text { volume }(\mathrm{mL})\end{array}$ & $14.28(11.94,16.23)$ & $13.21^{\mathrm{a}}(11.28,15.49)$ & $10.78^{\mathrm{ab}}(8.56,13.17)$ & $6.14^{\mathrm{abc}}(3.25,8.93)$ & $\begin{array}{c}13.92^{\mathrm{cd}}(11.39 \\
17.31)\end{array}$ & $13.07(10.57,15.53)$ \\
\hline Emean (kPa) & $1.70(1.55,1.99)$ & $1.75(1.55,1.95)$ & $1.95^{\mathrm{ab}}(1.65,2.30)$ & $2.45^{\mathrm{abc}}(2.03,3.10)$ & $1.65^{\mathrm{cd}}(1.50,1.95)$ & $1.75(1.56,2.05)$ \\
\hline Emax (kPa) & $2.65(2.45,2.90)$ & $2.80^{\mathrm{a}}(2.55,3.30)$ & $3.78^{\mathrm{ab}}(2.84,5.45)$ & $7.55^{\mathrm{abc}}(4.58,11.55)$ & $2.65^{\mathrm{cd}}(2.45,3.25)$ & $2.80(2.50,3.45)$ \\
\hline $\begin{array}{l}\text { E[max-min] } \\
(\mathrm{kPa})\end{array}$ & $1.15(1.00,1.40)$ & $1.65^{\mathrm{a}}(1.40,2.05)$ & $2.53^{\mathrm{ab}}(1.70,4.48)$ & $6.25^{\mathrm{abc}}(3.63,10.65)$ & $1.70^{\mathrm{cd}}(1.33,2.10)$ & $1.60(1.35,2.20)$ \\
\hline $\begin{array}{l}\text { Total sperm } \\
\text { count }\left(\times 10^{6}\right)\end{array}$ & $\begin{array}{c}193.89(133.25 \\
306.15)\end{array}$ & $\begin{array}{c}135.97(88.57 \\
215.22)\end{array}$ & $13.00(4.02,29.96)$ & 0 & 0 & $\begin{array}{c}130.84(39.62 \\
227.94)\end{array}$ \\
\hline
\end{tabular}

Group I: normozoospermia; Group II: normozoospermia with decreased motility and agglutination; Group II: oligozoospermia. ${ }^{\dagger}$, the median (25th, 75th percentile); ${ }^{a}$, compared with Group I, $\mathrm{P}<0.01 ;{ }^{\mathrm{b}}$, compared with Group II, $\mathrm{P}<0.01$; ${ }^{\mathrm{c}}$, compared with Group III, $\mathrm{P}<0.01$;

d, compared with Group-NOA, $\mathrm{P}<0.01$. Emean, mean elastic modulus; Emin, minimum elastic modulus; Emax, maximum elastic modulus;

E[max-min], maximum minus the minimum elastic modulus; OA, obstructive azoospermia; NOA, non-obstructive azoospermia.

I and Group II $(\mathrm{P}>0.05)$.

\section{The correlation between sperm concentration and either testicular volume or testicular elastic modulus}

Testicular volume was positively correlated with sperm concentration (correlation coefficient; $r=0.476 ; \mathrm{P}<0.01$ ). We found that the Emax, Emean, and E[max-min] were negatively correlated with sperm concentration $(r=-0.511$, -0.357 , and -0.524 , respectively; $\mathrm{P}<0.01$ ).

\section{The diagnostic value of testicular elastic modulus (Figure 1)}

\section{Group-OA vs. Group-NOA}

In Group-OA, 10 cases of epididymal stasis and 14 cases of epididymal atresia were found by conventional ultrasound. A total of 11 cases of seminal vesicle dysplasia were found by pelvic computed tomography (CT), and no imaging abnormality was found in 6 cases.

In Group-NOA, pituitary tumors were found in 2 cases by magnetic resonance imaging (MRI). The distribution of Y-chromosome microdeletions at the AZF locus, polymorphisms, and autosomal abnormalities in GroupNOA are shown in Table 1.
A pathomorphological analysis of the testicular biopsy of 25 azoospermia males was performed according to the Johnsen score. This showed that 8 cases had decreased spermatogenic function (8-9 points) and belonged to Group-OA. The remaining 17 cases of azoospermia participants belonged to Group-NOA, and included 2 cases (6-7 points) with sperm cell differentiation disorder, 3 cases (4-5 points) with delayed maturation of primary spermatocytes, 2 cases ( 3 points) with spermatogonial block, and 10 cases with Sertoli cell only syndrome (SCOS) (less than 2 points).

The differential diagnosis of OA and NOA participants, as well as the Emax, Emean, and E[max-min] ROC curves, are shown in Table 3 and Figure 1.

Group I, Group II, and mild oligozoospermia subgroup $v s$. severe oligozoospermia subgroup and Group-NOA A total of 138 participants in Group III had oligozoospermia and were classified into either a mild or severe subgroup. Their general information is shown in Table 4.

The detection rate of chromosome abnormality was significantly higher in the severe oligozoospermia subgroup and Group-NOA. The differential diagnosis of the severe oligozoospermia subgroup and Group-NOA vs. Group I, 
Table 3 Differential diagnosis with ROC curves

\begin{tabular}{|c|c|c|c|c|c|c|c|}
\hline $\begin{array}{l}\text { Differential } \\
\text { diagnosis item }\end{array}$ & SWE parameter & AUC & $95 \% \mathrm{Cl}$ & $\begin{array}{l}\text { Cut-off value } \\
\qquad(\mathrm{kPa})\end{array}$ & $\begin{array}{l}\text { Highest Youden } \\
\text { index }\end{array}$ & $\begin{array}{c}\text { Sensitivity } \\
(\%)\end{array}$ & $\begin{array}{l}\text { Specificity } \\
(\%)\end{array}$ \\
\hline \multirow{2}{*}{$\begin{array}{l}\text { Group-OA vs. } \\
\text { Group-NOA }\end{array}$} & Emax & 0.910 & $0.861-0.959$ & 3.525 & 0.705 & 87.6 & 82.9 \\
\hline & $E[\max -\min ]$ & 0.900 & $0.850-0.951$ & 2.675 & 0.726 & 84.8 & 87.8 \\
\hline \multirow{2}{*}{$\begin{array}{l}\text { Subgroup-severe } \\
\text { oligozoospermia } \\
\text { and Group-NOA } \\
\text { vs. other groups }\end{array}$} & Emean & 0.791 & $0.749-0.833$ & 2.025 & 0.467 & 66.5 & 80.2 \\
\hline & $E[\max -\min ]$ & 0.878 & $0.845-0.911$ & 2.625 & 0.633 & 72.3 & 91.0 \\
\hline
\end{tabular}

SWE, shear wave elastography; Emean, mean elastic modulus; Emin, minimum elastic modulus; Emax, maximum elastic modulus; $\mathrm{E}$ [max-min], maximum minus the minimum elastic modulus; ROC, receiver operating characteristic; $\mathrm{AUC}$, area under the ROC curve; $\mathrm{Cl}$, confidence interval; OA, obstructive azoospermia; NOA, non-obstructive azoospermia.

Table 4 General information of mild and severe oligozoospermia subgroups

\begin{tabular}{lccccc}
\hline Group & $\mathrm{N}$ & Sperm concentration & Emax & Emean & E[max-min] \\
\hline Mild subgroup & 70 & $<5 \times 10^{6} / \mathrm{mL}$ & $3.55^{\#}(2.65,4.91)$ & $1.78(1.60,2.10)$ & $2.25(1.59,4.14)$ \\
Severe subgroup & 68 & $5 \times 10^{6} / \mathrm{mL}-15 \times 10^{6} / \mathrm{mL}$ & $4.03^{* *}(3.01,6.13)$ & $2.05^{*}(1.70,2.44)$ & $2.68^{* * *}(1.81,5.23)$ \\
\hline
\end{tabular}

\#, the median (25th, 75th percentile); comparisons of mild and severe oligozoospermia subgroup, ${ }^{*}, \mathrm{P}<0.05,{ }^{* *}, \mathrm{P}<0.01,{ }^{* \star *}, \mathrm{P}=0.05$. Emean, mean elastic modulus; Emin, minimum elastic modulus; Emax, maximum elastic modulus; E[max-min], maximum minus the minimum elastic modulus.

Group II, and mild oligozoospermia subgroup, as well as the Emax, Emean, and E[max-min] ROC curves, are shown in Table 3 and Figure 1.

\section{Discussion}

Defective spermatogenesis is one of the most common causes of male subfertility in human populations. Semen analysis and biopsy-determined histological scores are widely accepted evaluation methods for defective spermatogenesis. Semen analysis is still the gold standard for the assessment of male infertility, with clear guidelines provided by national associations such as the American Urological Association (AUA) and the American Society for Reproductive Medicine (ASRM) (22). Compared with many other examinations used in the assessment of male infertility, semen analysis has globally been standardized. However, the semen analysis of the same person varies with different ejaculations. This may be caused by preanalytic influences such as duration of abstinence or seasonality, analytic variation in the method, and inherent biologic variability (23). A single sample is not sufficient to evaluate any abnormalities in the results of semen analysis, therefore repeat semen analysis is necessary. Testicular histopathology is often considered the gold standard for determining testicular damage non-clinically. However, the invasiveness of this technique restricts its broad clinical application. Of the assisted reproductive techniques, IVF is the most commonly used to help infertile couples conceive. Currently, literature supports the use of ejaculated sperm in preference to testicular sperm (other than in the case of high sperm DNA fragmentation), especially where sperm numbers are extremely low (24). Provided that ejaculated sperm is available, there is no need for invasive diagnostic and therapeutic procedures on the testes. With the development of microscopic sperm extraction techniques, diagnostic needle biopsies have been further reduced in NOA patients. There is an urgent clinical need for a noninvasive and simple method that can evaluate changes in spermatogenic function and testicular histopathology.

Fibrotic thickening in the walls of seminiferous tubules in the testes is observed in men with impaired spermatogenesis, making fibrosis a hallmark of male infertility (25). Differentiation between normal tissue and pathological tissue with an altered elasticity and increased stiffness, such as occurs in the fibrotic process, 
can be achieved with SWE. Essentially, this means that the spermatogenic function of the testis is closely related to testicular elasticity $(17,18)$, and is consistent with our research conclusions.

In our study, we measured the central part of the testis, which was determined by the anatomical structure of the testis and the characteristics of the SWE technique. We did so for various reasons: firstly, the stiffness of the testicular capsule is greater than that of the testicular parenchyma, while the testicular mediastinum also increases the stiffness of the surrounding testis. Secondly, SWE does not require the sonographer to manually press the scrotum with a transducer. However, in most cases, the probe will inevitably exert some pressure on the scrotal surface. The measurement errors of SWE elastic modulus caused by these human factors impact more significantly on the surrounding region of the testicular parenchyma than on the central region. Therefore, in order to obtain more reliable and repeatable data, we chose the central part of the testes to be measured 3 times. More measurements would have yielded more precise estimates, but it was only possible to obtain 3 SWE measurements of each testis due to the daily workflow in the department of ultrasound in our hospital. This was also a limitation of our study.

A new index of $\mathrm{E}$ [max-min] was included in this study. Herwig et al. (26) found that the difference in microvascular perfusion of ultrasound contrast agents in each area of the testis was related to spermatogenesis. The more obvious the difference in testicular microperfusion, the more uneven the testicular parenchyma, and the worse the spermatogenic function of the testis. Our research had reached the same conclusion, and in our study, the E[max-min] represented the difference between the maximum elasticity and the minimum elasticity in the ROI. The greater the difference of $\mathrm{E}[\mathrm{max}-\mathrm{min}]$, the higher the degree of heterogeneity of the testicular parenchyma. The E[max-min] in the participants of the Group-NOA and severe oligozoospermia subgroup was much greater than those of other groups. In addition, when distinguishing between OA and NOA, the specificity of E[max-min] was $87.8 \%$, which was higher than that of the Emax (82.9\%) and Emean (80.5\%). When distinguishing men with NOA and severe oligozoospermia from those with normozoospermia, normozoospermia with decreased motility and agglutination, and mild oligozoospermia, its specificity was $91.0 \%$, which was much higher than that of the Emax (79.6\%) and Emean (80.2\%). We found that the E[max-min] could indirectly reflect the spermatogenic function of the testis, with a higher value of
$\mathrm{E}$ [max-min] reflecting a worse spermatogenic function of testis. Its specificity was also higher than that of the Emax and Emean.

It is widely accepted that testicular volume is a standard for evaluating testicular spermatogenic function in clinical work as there is a positive correlation between testicular volume and sperm count $(27,28)$. The decrease of testicular volume could reflect the degree of testicular parenchymal damage. The smaller the testis, the more severe the damage of the testicular parenchyma (19). However, in a recent study of NOA, $36 \%$ of patients were found to have normal testicular volume, and $64 \%$ had smaller testes (29). This suggests that it is not sufficient to use testicular volume alone to evaluate the spermatogenic function of testis. Men with azoospermia require testicular sperm extraction to obtain mature sperm. Many researchers try to predict the success rate of sperm extraction by measuring testicular volume. A study showed that testicular volume in azoospermic men with a history of bilateral cryptorchidism might be an effective predictive factor for successful sperm recovery with micro-testicular sperm extraction (30). In contrast, another study showed that testicular volume had limited value in predicting the success rate of sperm extraction in OA patients (31). With this in mind, we believe that in addition to testicular volume, more emphasis should be placed on discovering more predictive assessment methods for male factor infertility.

Azoospermia is easily diagnosed by semen analysis, but there are some difficulties in the differential diagnosis of $\mathrm{OA}$ and NOA. Some men are still unable to obtain a definite diagnosis via assessment of their medical history, physical examination, endocrine analysis, imaging examination, and chromosome analysis. They must therefore rely on testicular histological biopsies to confirm the diagnosis. However, few patients consent to testicular histological biopsy because of its invasiveness. Moreover, the etiologies of OA are well studied and distinct from those of $\mathrm{NOA}$, and the sperm retrieval rates are relatively higher in OA subjects. Elastic modulus had certain reliability in the differential diagnosis of OA and NOA. In our study, the AUC of Emax, E[max-min], and Emean in the differential diagnosis of OA and NOA were 0.910, 0.900 , and 0.863 , respectively. When Emax was $>3.525 \mathrm{kPa}$, $\mathrm{E}$ [max-min] $>2.675 \mathrm{kPa}$, or Emean $>2.025 \mathrm{kPa}$, SWE could highly indicate the possibility of NOA.

Mutations and genotypes of genes regulating the spermatogenesis process may lead to male infertility (32). Identifying the genetic risk factors can help the assisted reproductive technologists to improve both the treatment and counselling of affected men. The results of this study 
showed that only the severe oligozoospermia subgroup and Group-NOA participants had microdeletions in the AZF region of the $\mathrm{Y}$ chromosome. These microdeletions were present in as many as $5.88 \%$ and $9.52 \%$ of severe oligospermic and azoospermic men, respectively. These results appear consistent with other research which found that men with very low sperm counts had a higher incidence of Y-chromosome microdeletions (33). It has been reported that single genetic anomalies (including point mutations and chromosome aberrations) could be responsible for around $25 \%$ of NOA patients (34). Consistent with the literature, this research found that the incidence of autosomal abnormalities increased significantly with the decrease of sperm concentration, and suddenly increased to $22.86 \%$ in the Group-NOA. For this reason, we used ROC curve to analyze the diagnostic ability of elastic modulus in NOA and severe oligozoospermia. The AUC of Emax, E[maxmin], Emean were 0.877, 0.878 and 0.791, respectively. When Emax $>3.275 \mathrm{kPa}, \mathrm{E}[\max -\min ]>2.625 \mathrm{kPa}$, or Emean $>2.025 \mathrm{kPa}$, the possibility of severe spermatogenic dysfunction was indicated, and we strongly recommended the men undergo chromosome analysis.

In our study, it was recommended that two specimens be used to diagnose abnormal spermatogenesis (35). To confirm this, we conducted repeat semen analysis 7 days after the first sampling of men with abnormal semen results. The infertile couples were examined together to prepare for assisted reproductive treatments. To improve the efficiency of assisted reproductive treatments, we designated a shorter time for repeat sample collection. However, previous literature reported that a significant correlation was observed within the first 2 weeks of the repeat sample collection for most semen parameters (35). This correlation may make the results of repeated measurements meaningless. In addition, to facilitate a more natural approach to pregnancy, we selected the better semen result when deciding upon the assisted reproduction procedure. Nevertheless, it remained unclear which sample better represented the true value, and this may have led to selective bias.

A strength of this study was the size of the sample. However, the study still had several shortcomings. First of all, the findings may not be generalizable as the study was not population based, having only enrolled men taking part in an IVF-assisted pregnancy in a single-institution setting. Secondly, the results of testicular elastic modulus showed a high degree of overlap in Group I, Group II, the mild oligozoospermia subgroup, and Group-OA. The diagnostic utility of SWE in mild spermatogenic dysfunction remains limited. Thirdly, the histopathologic diagnosis of hypospermatogenesis could not be obtained in this study. For this reason, we had to forgo histological results and use semen parameters as the indicators of testicular damage. Lastly, we did not take the effects of obesity on testicular parenchyma and sperm quality into account.

\section{Conclusions}

In this paper, real-time SWE was used to quantitatively analyze the elastic modulus of testis. After comparing the elastic modulus of testis with conventional semen parameters, we found that the elastic modulus values of testis were negatively correlated with semen results. From this we determined that SWE, as an effective supplement to routine ultrasound examination, can be used to diagnose and differentiate spermatogenic dysfunction.

\section{Acknowledgments}

We acknowledge and thank our study participants. We also thank the triage nurses for assisting us with the data collection.

Funding: None.

\section{Footnote}

Reporting Checklist: The authors have completed the STROBE reporting checklist. Available at https://dx.doi. org/10.21037/qims-21-648

Conflicts of Interest: All authors have completed the ICMJE uniform disclosure form (available at https://dx.doi. org/10.21037/qims-21-648). The authors have no conflicts of interest to declare.

Ethical Statement: The authors are accountable for all aspects of the work in ensuring that questions related to the accuracy or integrity of any part of the work are appropriately investigated and resolved. The study was conducted in accordance with the Declaration of Helsinki (as revised in 2013). The study was approved by the ethics committee of Shengjing Hospital of China Medical University (2018PS104J). Written informed consent was provided by all participants.

Open Access Statement: This is an Open Access article distributed in accordance with the Creative Commons 
Attribution-NonCommercial-NoDerivs 4.0 International License (CC BY-NC-ND 4.0), which permits the noncommercial replication and distribution of the article with the strict proviso that no changes or edits are made and the original work is properly cited (including links to both the formal publication through the relevant DOI and the license). See: https://creativecommons.org/licenses/by-nc-nd/4.0/.

\section{References}

1. Mascarenhas MN, Flaxman SR, Boerma T, Vanderpoel S, Stevens GA. National, regional, and global trends in infertility prevalence since 1990: a systematic analysis of 277 health surveys. PLoS Med 2012;9:e1001356.

2. Datta J, Palmer MJ, Tanton C, Gibson LJ, Jones KG, Macdowall W, Glasier A, Sonnenberg P, Field N, Mercer $\mathrm{CH}$, Johnson AM, Wellings K. Prevalence of infertility and help seeking among 15000 women and men. Hum Reprod 2016;31:2108-18.

3. Suvannarerg V, Chitchumnong P, Apiwat W, Lertdamrongdej L, Tretipwanit N, Pisarnturakit P, Sitthinamsuwan $\mathrm{P}$, Thiravit S, Muangsomboon K, Korpraphong P. Diagnostic performance of qualitative and quantitative shear wave elastography in differentiating malignant from benign breast masses, and association with the histological prognostic factors. Quant Imaging Med Surg 2019;9:386-98.

4. Han RJ, Du J, Li FH, Zong HR, Wang JD, Shen YL, Zhou QY. Comparisons and Combined Application of Two-Dimensional and Three-Dimensional Realtime Shear Wave Elastography in Diagnosis of Thyroid Nodules. J Cancer 2019;10:1975-84.

5. Chae SY, Jung HN, Ryoo I, Suh S. Differentiating cervical metastatic lymphadenopathy and lymphoma by shear wave elastography. Sci Rep 2019;9:12396.

6. Flatres A, Aarab Y, Nougaret S, Garnier F, Larcher R, Amalric M, Klouche K, Etienne P, Subra G, Jaber S, Molinari N, Matecki S, Jung B. Real-time shear wave ultrasound elastography: a new tool for the evaluation of diaphragm and limb muscle stiffness in critically ill patients. Crit Care 2020;24:34.

7. Korta Martiartu N, Nakhostin D, Ruby L, Frauenfelder T, Rominger MB, Sanabria SJ. Speed of sound and shear wave speed for calf soft tissue composition and nonlinearity assessment. Quant Imaging Med Surg 2021;11:4149-61.

8. Marcon J, Trottmann M, Rübenthaler J, D'Anastasi M, Stief CG, Reiser MF, Clevert DA. Three-dimensional vs. two-dimensional shear-wave elastography of the testes - preliminary study on a healthy collective. Clin Hemorheol Microcirc 2016;64:447-56.

9. Chen F, Mao L, Zhou X, Qiao X, Luo Y, Zhu Z, Chen R, Qiu S, Zeng B. Application of Shear Wave Elastography to Evaluate the Stiffness of Normal Testes and Inflammatory Epididymal Tail Masses. Ultrasound Q 2020;37:161-7.

10. Pedersen MR, Møller H, Osther PJS, Vedsted P, Holst R, Rafaelsen SR. Comparison of Tissue Stiffness Using Shear Wave Elastography in Men with Normal Testicular Tissue, Testicular Microlithiasis and Testicular Cancer. Ultrasound Int Open 2017;3:E150-5.

11. Abdelwahab K, Eliwa AM, Seleem MM, El Galaly H, Ragab A, Desoky EA, Naguib M, Ali MM, Saber S, Kamel H. Role of Preoperative Testicular Shear Wave Elastography in Predicting Improvement of Semen Parameters After Varicocelectomy for Male Patients With Primary Infertility. Urology 2017;107:103-6.

12. Fuschi A, Capone L, Abuorouq S, Al Salhi Y, Velotti G, Aversa S, Carbone F, Maceroni P, Petrozza V, Carbone A, Pastore AL, Porta N. Shear wave elastography in varicocele patients: Prospective study to investigate correlation with semen parameters and histological findings. Int J Clin Pract 2021;75:e13699.

13. Turna O, Aybar MD. Testicular stiffness in varicocele: evaluation with shear wave elastography. Ultrasonography 2020;39:350-5.

14. Turna $\mathrm{O}$, Alis D. A comparative study of shear wave elastography in the evaluation of undescended and retractile testes in a pediatric population. J Med Ultrason (2001) 2019;46:231-7.

15. Pedersen MR, Osther PJ, Rafaelsen SR. Testicular microlithiasis and preliminary experience of acoustic radiation force impulse imaging. Acta Radiol Open 2016;5:2058460116658686.

16. Aslan S, Ceyhan Bilgici M, Saglam D, Ozturk M. The role of ARFI elastography to evaluate microstructrual changes of patients with testicular microlithiasis. Acta Radiol 2018;59:1517-22.

17. Yavuz A, Yokus A, Taken K, Batur A, Ozgokce M, Arslan H. Reliability of testicular stiffness quantification using shear wave elastography in predicting male fertility: a preliminary prospective study. Med Ultrason 2018;20:141-7.

18. Rocher L, Criton A, Gennisson JL, Izard V, Ferlicot S, Tanter M, Benoit G, Bellin MF, Correas JM. Testicular Shear Wave Elastography in Normal and Infertile Men: A Prospective Study on 601 Patients. Ultrasound Med Biol 2017;43:782-9. 
19. Erdoğan H, Durmaz MS, Özbakır B, Cebeci H, Özkan D, Gökmen İE. Experience of using shear wave elastography in evaluation of testicular stiffness in cases of male infertility. J Ultrasound 2020;23:529-34.

20. Krausz C, Hoefsloot L, Simoni M, Tüttelmann F; European Molecular Genetics Quality Network. EAA/ EMQN best practice guidelines for molecular diagnosis of Y-chromosomal microdeletions: state-of-the-art 2013. Andrology 2014;2:5-19.

21. Cai D, Wu S, Li Y, Chen Q. Validity of measurements of testicular volume obtained by a built-in software of ultrasound systems: with formula recommended by updated guidelines as reference. J Ultrason 2020;20:e181-4.

22. Practice Committee of the American Society for Reproductive Medicine. Report on optimal evaluation of the infertile male. Fertil Steril 2006;86:S202-9.

23. Leushuis E, van der Steeg JW, Steures P, Repping S, Bossuyt PM, Blankenstein MA, Mol BW, van der Veen F, Hompes PG. Reproducibility and reliability of repeated semen analyses in male partners of subfertile couples. Fertil Steril 2010;94:2631-5.

24. Esteves SC, Roque M, Garrido N. Use of testicular sperm for intracytoplasmic sperm injection in men with high sperm DNA fragmentation: a SWOT analysis. Asian J Androl 2018;20:1-8.

25. Shiraishi K, Takihara H, Naito K. Quantitative analysis of testicular interstitial fibrosis after vasectomy in humans. Aktuelle Urol 2003;34:262-4.

26. Herwig R, Tosun K, Schuster A, Rehder P, Glodny B, Wildt L, Illmensee K, Pinggera GM. Tissue perfusioncontrolled guided biopsies are essential for the outcome of testicular sperm extraction. Fertil Steril 2007;87:1071-6.

27. MacLeod J, Wang Y. Male fertility potential in terms of semen quality: a review of the past, a study of the present. Fertil Steril 1979;31:103-16.

Cite this article as: Cui J, Du Q, Fu W. Application of realtime shear wave elastography in the assessment of male infertility. Quant Imaging Med Surg 2022;12(2):1505-1516. doi: 10.21037/qims-21-648
28. Handelsman DJ, Conway AJ, Boylan LM, Turtle JR. Testicular function in potential sperm donors: normal ranges and the effects of smoking and varicocele. Int $\mathrm{J}$ Androl 1984;7:369-82.

29. Abdelaal AMA, El-Azizi HM, GamalEl Din SF, Abdulsalam Mohammad Azzazi O, Shokr Mohamed M. Evaluation of the potential role of shear wave elastography as a promising predictor of sperm retrieval in nonobstructive azoospermic patients: A prospective study. Andrology 2021;9:1481-9.

30. Osaka A, Iwahata T, Kobori Y, Shimomura Y, Yoshikawa N, Onota S, Yamamoto A, Ide H, Sugimoto K, Okada H. Testicular volume in non-obstructive azoospermia with a history of bilateral cryptorchidism may predict successful sperm retrieval by testicular sperm extraction. Reprod Med Biol 2020;19:372-7.

31. Li H, Chen LP, Yang J, Li MC, Chen RB, Lan RZ, Wang SG, Liu JH, Wang T. Predictive value of FSH, testicular volume, and histopathological findings for the sperm retrieval rate of microdissection TESE in nonobstructive azoospermia: a meta-analysis. Asian J Androl 2018;20:30-6.

32. Cerván-Martín M, Castilla JA, Palomino-Morales RJ, Carmona FD. Genetic Landscape of Nonobstructive Azoospermia and New Perspectives for the Clinic. J Clin Med 2020;9:300.

33. Goncalves C, Cunha M, Rocha E, Fernandes S, Silva J, Ferraz L, Oliveira C, Barros A, Sousa M. Y-chromosome microdeletions in nonobstructive azoospermia and severe oligozoospermia. Asian J Androl 2017;19:338-45.

34. Krausz C, Riera-Escamilla A. Genetics of male infertility. Nat Rev Urol 2018;15:369-84.

35. Agarwal A, Baskaran S, Parekh N, Cho CL, Henkel R, Vij S, Arafa M, Panner Selvam MK, Shah R. Male infertility. Lancet 2021;397:319-33. 